\title{
High-density Grid Technology Aids in the Visualization of Purkinje Potentials in Fascicular Ventricular Tachycardia
}

\author{
DEEPAK SALUJA, MD, ${ }^{1}$ GEOFFREY A. RUBIN, MD, ${ }^{1}$ MARK P. ABRAMS, MD, ${ }^{1}$ JEREMY P. BERMAN, MD, ${ }^{1}$ \\ ELAINE Y. WAN, MD, ${ }^{1}$ ANGELO BIVIANO, MD, $\mathrm{MPH}^{1}{ }^{1}$ and HASAN GARAN, $\mathrm{MD}^{1}$
}

${ }^{1}$ Electrophysiology Section, Division of Cardiology, Department of Medicine, Columbia University Vagelos College of Physicians and Surgeons, New York, NY, USA

KEYWORDS. Purkinje potentials, right bundle branch block, ventricular tachycardia.

ISSN 2156-3977 (print) ISSN 2156-3993 (online) CC BY 4.0 license

(c) 2021 Innovations in Cardiac Rhythm Management
A 71-year-old man with atrial fibrillation (AF), ischemic cardiomyopathy, and ventricular tachycardia (VT) presented having experienced implantable cardioverter-defibrillator (ICD) shocks. He had been previously treated with amiodarone and ICD placement for VT. His last episode of VT was several years prior to admission. About two months before admission, several appropriate shocks were recorded. Despite an increase in amiodarone, in subsequent weeks, he received several additional shocks with syncope. He was hospitalized and an unchanged ejection fraction of $35 \%$, patent bypass grafts, and no new coronary disease were documented. He was then transferred to our institution.

In the electrophysiology laboratory, the baseline rhythm was AF with left bundle branch block (LBBB) and an $\mathrm{H}-\mathrm{V}$ interval of $59 \mathrm{~ms}$. Voltage mapping of the left ventricle

Dr. Saluja has served as a consultant to Abbott and Biosense Webster. Dr. Wan has served on steering committees for Medtronic and Boston Scientific and has received National Institutes of Health funding for research not related to this article. Dr. Biviano has served as a medical advisory board member for Abbott, Boston Scientific, and Biosense Webster. The other authors report no conflicts of interest for the published content.

Address correspondence to: Deepak Saluja, MD.

Email: ass16@cumc.columbia.edu.
(LV) endocardium with the Advisor ${ }^{\mathrm{TM}}$ HD Grid Mapping Catheter, Sensor Enabled ${ }^{\mathrm{TM}}$ revealed only a small area of scar in the anteroseptal LV. During mapping, incessant, repetitive episodes of VT no. 1 (VT1) occurred with an $\mathrm{H}-\mathrm{V}$ interval of $79 \mathrm{~ms}$ (Figure 1). Attempts at entrainment from the right ventricle repeatedly led to termination. Bundle-branch reentry VT was diagnosed and ablation of the right bundle led to the cessation of VT1.

Subsequently, repetitive episodes of a right-bundle, superior-axis morphology VT no. 2 (VT2) were seen. Intracardiac electrograms and a 12-lead electrocardiogram suggested an origin near the left posterior hemifascicle (Figure 2). Entrainment attempts from this area led to termination. The Advisor ${ }^{\mathrm{TM}}$ HD Grid catheter was placed in this region (Figure 3), demonstrating a fascicular potential of about $50 \mathrm{~ms}$ pre-QRS and retrograde Purkinje potentials. Ablation at this site resulted in termination of the repetitive VT2 salvos (Video 1). The patient remained without further sustained VT at three months of follow-up.

This case suggests the Advisor ${ }^{\mathrm{TM}}$ HD Grid catheter is useful in rapidly identifying the presence and direction of conduction of fascicular potentials during the ablation of fascicular VT. 


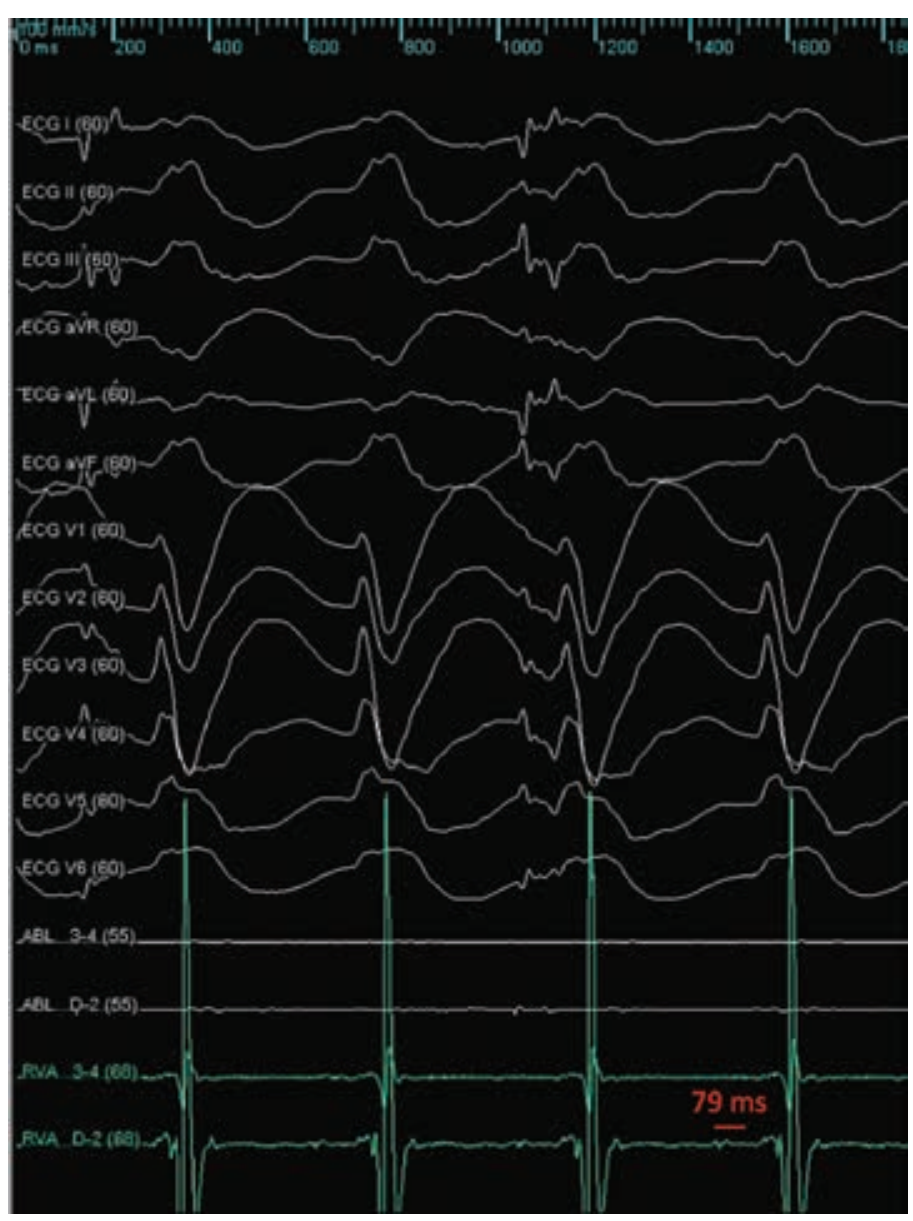

Figure 1: The baseline rhythm was AF with LBBB conduction and an $\mathrm{H}-\mathrm{V}$ interval of $59 \mathrm{~ms}$. VT1, repetitively initiated with catheter manipulation, had an $\mathrm{H}-\mathrm{V}$ interval of $79 \mathrm{~ms}$, suggestive of bundle-branch reentry VT. Attempts at entrainment led to termination. Ablation of the right bundle was performed with subsequent cessation of the VT. In this figure, the right ventricular catheter is in the His position. 


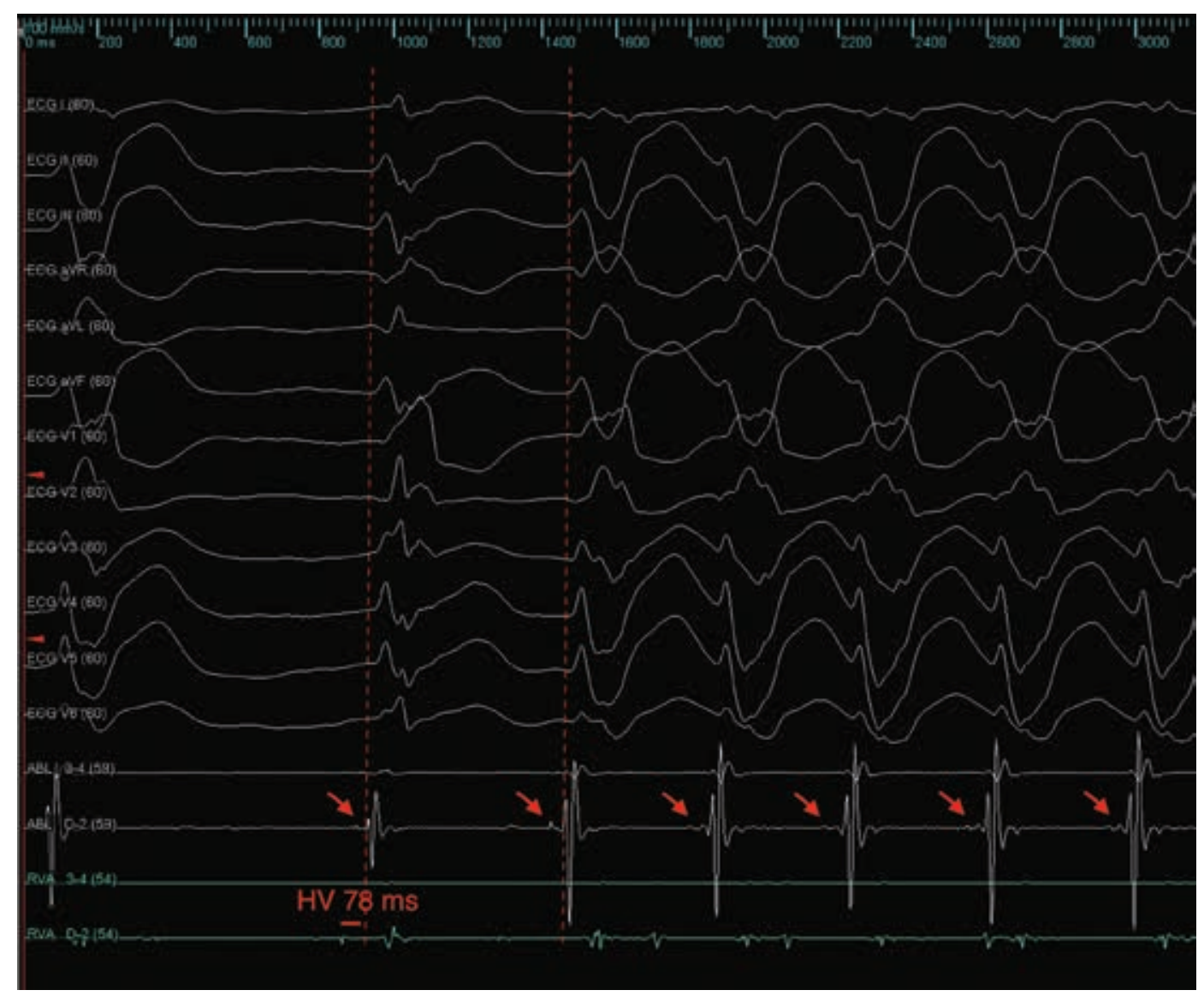

Figure 2: Repetitive episodes of VT were seen. The conducted QRS was a right-bundle type with a prolonged H-V interval after ablation of the right bundle. The ablation catheter is in the region of the left posterior hemifascicle. The potential QRS time was roughly $20 \mathrm{~ms}$ both in sinus rhythm and VT (arrows), suggesting the catheter was located at or downstream of a fascicular origin of the VT. In this figure, the right ventricular catheter is in the His position. 


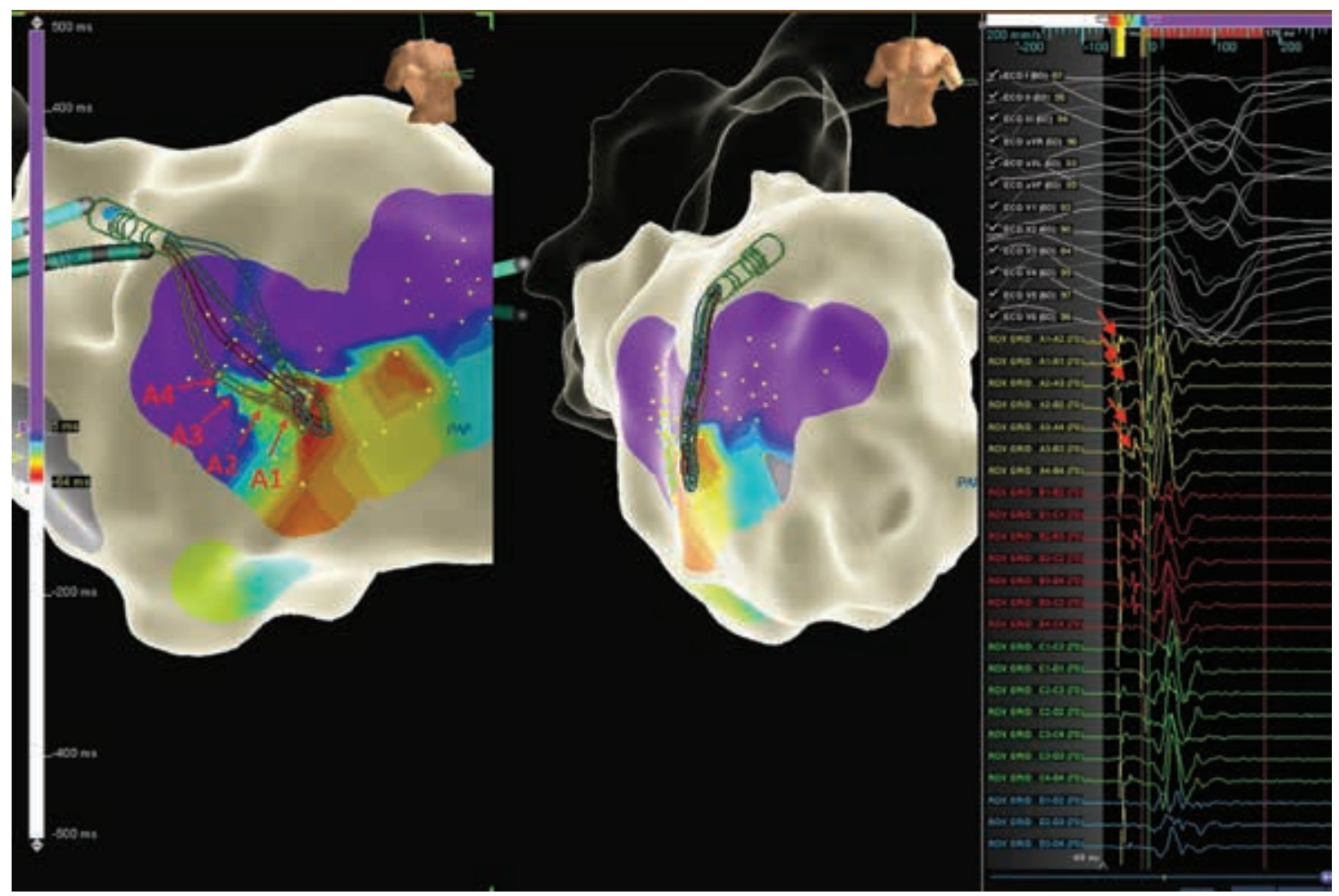

Figure 3: AdvisorTM HD Grid signals showed the earliest Purkinje signals were at about 50 ms pre-QRS (A1-A2), with retrograde activation of Purkinje potentials evident (arrowheads). 